\title{
Comparison of Tramadol and Pethidine for Control of Shivering Following Central Neuraxial Blockade
}

\author{
Prameela VS', Madhu Kumar BS ${ }^{1}$, Brijesh Kumar ${ }^{2}$ \\ ${ }^{1}$ Assistant Professor, Department of Anaesthesiology, Akash institute of Medical Sciences and Research Centre, Devanahalli, Bengaluru, Karnataka, India, \\ ${ }^{2}$ Associate Professor, Department of Anaesthesiology, Akash institute of Medical Sciences and Research Centre, Devanahalli, Bengaluru, Karnataka, India.
}

\section{Abstract}

Background: Central neuraxial blockade is associated with shivering in 40-60\% of the patients. A popularly used drug to control shivering is pethidine. The present study was conducted to evaluate the effect of tramadol on shivering and compare it with the efficacy of pethidine. The study was also intended to compare the haemodynamics, complications and recurrence of shivering with the use of pethidine and tramadol. Subjects and Methods: This prospective comparative study was conducted in Department of Anaesthesiology, Akash Institute of Medical Sciences and Research Centre, Devanahalli, Bengaluru. In this study, 80 consenting patients of either gender, aged between 20-60 years, in American Society of Anesthesiologists (ASA) Grades 1, 2 and 3 according to ASA who experienced shivering during or immediately after elective surgeries under central neuraxial blockade (spinal, epidural and combined spinal and epidural) were randomized to receive either pethidine $1 \mathrm{mg} / \mathrm{kg}$ or tramadol $1 \mathrm{mg} / \mathrm{kg}$ for control of shivering. The time interval for the onset of shivering after regional anaesthesia, onset of disappearance of shivering after drug administration, complete disappearance of shivering, hemodynamics, recurrence of shivering and complications were recorded. Results: There was no statistical difference in the onset of disappearance between the 2 groups ( $\mathrm{p}=0.615$ ). Time taken for complete disappearance of shivering after 5 minutes interval period was statistically more in Group T (17.5\% vs 5\% in Group P) with $\mathrm{p}=0.154$. Recurrence of shivering occurred more in the tramadol group as compared to pethidine group which was strongly significant statistically $(27.5 \%$ vs $5.0 \%)$ with $\mathrm{p}=0.006$. However the incidence of complications was higher with pethidine with a greater drop in mean blood pressure, increased indicators of respiratory depression, more sedation, greater nausea, vomiting and itching. Conclusion: The present study results may conclude that tramadol is an effective drug in the control of shivering with more stable hemodynamic and fewer side effects such as sedation, respiratory depression, nausea, vomiting and itching. However one must be prepared for a slight delay in the onset of its action and expect a recurrence of shivering which may require further therapy. Pethidine, with its equal efficacy may be advocated in patients allergic to tramadol and where sedation is desirable.

Keywords: Central neuraxial blockade, shivering, Tramadol, Pethidine.

Corresponding Author: Dr. Brijesh Kumar, Assistant Professor, Department of Anaesthesiology, Akash institute of Medical Sciences and Research Centre, Devanahalli, Bengaluru, Karnataka, India.

Email: bk29011977@gmail.com

Received: April 2020

Accepted: June 2020

\section{Introduction}

Regional anaesthesia with a central neuraxial block is a safe and popular technique for various surgeries. However, around $40-60 \%$ of the patients undergoing surgery under central neuraxial block develop shivering. Shivering can be very unpleasant and physiologically stressful for the patients. ${ }^{[1]}$ Shivering increases metabolic rate and oxygen consumption by $100-600 \%$. It may induce arterial hypoxemia, lactic acidosis, increased intraocular pressure and intracranial pressure. It also interferes with ECG monitoring, pulse oximetry, pulse rate and blood pressure recording. Shivering may also be detrimental to patients with low cardio respiratory reserves. ${ }^{[2]}$

Many attempts have been made to suppress or obtund this shivering. Modalities used include warming the patient and IV fluids as well as pharmacological therapy with the use of drugs such as pethidine, nefopam, physostigmine, tramadol, clonidine, alfentanyl, doxapram, ketanserin, ketamine, magnesium sulphate and ondansetron. ${ }^{[3]}$ Pethidine has been the most commonly used drug in this regard but it is getting more difficult to access as it is a 'protected drug'. It also has many side effects such as nausea, vomiting, sedation and respiratory depression. Tramadol hydrochloride is freely available and may be used for control of shivering. It is a centrally acting analgesic drug, a mu opioid agonist that also exerts a modulatory effect on central monoaminergic pathways, inhibiting the neuronal uptake of noradrenaline and serotonin. ${ }^{[4-6]}$

The present study was conducted to evaluate the effect of tramadol on shivering and compare it with the efficacy of pethidine. This study also compared the haemodynamics, complications and recurrence of shivering with the use of pethidine and tramadol. 


\section{Subjects and Methods}

This prospective comparative study was conducted in Department of Anaesthesiology, Akash Institute of Medical Sciences and Research Centre, Devanahalli, Bengaluru. In this study, 80 consenting patients of either gender, aged between 20-60 years, in ASA Grades 1, 2 and 3 patients according to American Society of Anesthesiologists (ASA)(1) who experienced shivering during or immediately after elective surgeries under regional anaesthesia (spinal, epidural and combined spinal and epidural) were included in the study. The patients were divided into two groups, 40 patients in Group $\mathrm{P}$ (received $1 \mathrm{mg} / \mathrm{kg}$ of pethidine intravenously) and 40 patients in Group T (received $1 \mathrm{mg} / \mathrm{kg}$ of tramadol intravenously) for control of shivering. The study was conducted after Institutional Ethical Committee clearance. Written informed consent was obtained from all the patients after explaining the methods. Exclusion criteria included patients who did not consent for the study, ASA grades 4 and 5, those with fever, thyroid disease, obesity, drug allergy, patients on long term phenothiazines and monoaminooxidase inhibitors or anticoagulants and patients who were shivering prior to the administration of the regional anaesthetic.

Pre-anaesthetic evaluation was performed in all the patients and haematological and biochemical investigations were reviewed. In the operating room the following parameters were monitored: pulse, non-invasive blood pressure, electrocardiogram, oxygen saturation, and temperature with a tympanic temperature probe

Central neuraxial blockade (subarachnoid block) was given as required by the surgical procedures. All the patients were covered with a thick cotton blanket soon after positioning. The operating theatre's temperature was maintained between 22 to $24^{\circ} \mathrm{C}$.

Prior to the administration of the study drug, the tympanic temperature and the hemodynamic parameters (pulse rate, mean blood pressure, $\mathrm{SpO} 2$ ) were recorded in all the patients. All the patients received ondansetron $4 \mathrm{mg}$ prophylactically following the administration of the study drug as per the decision made by the ethical committee not to subject patients to nausea and vomiting as both the study drugs are known to have high propensity for nausea and vomiting.

The subjects were then observed at regular intervals for the onset of shivering after regional anaesthesia, onset of disappearance of shivering after drug administration, complete disappearance of shivering, hemodynamics (pulse rate, mean blood pressure, SpO2), tympanic temperature, recurrence of shivering and complications if any. Based on the severity, the shivering was graded on a scale of $0-3$ as shown in [Table 1].

Table 1: Grade of shivering

\begin{tabular}{|l|l|}
\hline Grade 0 & No Shivering \\
\hline Grade 1 & $\begin{array}{l}\text { Mild fasciculations of face or neck, electrocardiogram } \\
\text { disturbances in absence of voluntary activity of arms }\end{array}$ \\
\hline Grade 2 & Visible tremors involving more than one group of muscle \\
\hline Grade 3 & $\begin{array}{l}\text { Gross muscular activity involving the entire body, bed } \\
\text { shaking }\end{array}$ \\
\hline
\end{tabular}

Patients who experienced recurrence of shivering received an additional dose of $0.5 \mathrm{mg} / \mathrm{kg}$ of either tramadol or pethidine in the respective groups.

\section{Statistical Methods:}

Descriptive statistical analysis has been used in the present study. Student t test (two tailed; independent) and Chi-square test has been used to test the homogeneity samples based on of age (or continuous parameters). Fisher Exact to test the homogeneity of samples based on parameters on categorical scale between two groups.

\section{Results}

A comparative clinical evaluation study was undertaken to study the efficacy of pethidine and tramadol for control of shivering following regional anaesthesia, the effect on haemodynamics, complications and the recurrence of shivering.

Table 2: Comparison of distribution of baseline parameters in patients of group $P$ and Group $T$

\begin{tabular}{|c|c|c|c|c|c|c|}
\hline \multirow[t]{2}{*}{ Parameters } & \multirow[t]{2}{*}{ Range } & \multicolumn{2}{|c|}{ Group P } & \multicolumn{2}{|c|}{ Group T } & \multirow{2}{*}{$\begin{array}{l}P \\
\text { value }\end{array}$} \\
\hline & & No & $\%$ & No & $\%$ & \\
\hline \multirow[t]{4}{*}{ Age in years } & $20-30$ & 24 & 60.0 & 30 & 75.0 & \multirow{4}{*}{0.384} \\
\hline & $31-40$ & 7 & 17.5 & 6 & 15.0 & \\
\hline & $41-50$ & 6 & 15.0 & 2 & 5.0 & \\
\hline & $51-60$ & 3 & 7.5 & 2 & 5.0 & \\
\hline \multirow[t]{2}{*}{ Gender } & Male & 10 & 25.0 & 7 & 17.5 & \multirow[t]{2}{*}{0.412} \\
\hline & Female & 30 & 75.0 & 33 & 82.5 & \\
\hline \multirow{3}{*}{$\begin{array}{l}\text { Duration of } \\
\text { surgery }\end{array}$} & $0-1 \mathrm{hrs}$ & 20 & 50.0 & 13 & 32.5 & \multirow[b]{3}{*}{0.120} \\
\hline & $1-2 \mathrm{hrs}$ & 19 & 47.5 & 22 & 55.0 & \\
\hline & $2-3 \mathrm{hrs}$ & 1 & 2.5 & 5 & 12.5 & \\
\hline \multirow[t]{2}{*}{ ASA grade } & ASA1 & 33 & 82.5 & 36 & 90.0 & \multirow[b]{2}{*}{0.330} \\
\hline & ASA 2 & 7 & 17.5 & 4 & 10.0 & \\
\hline
\end{tabular}

Table 3: Comparison of duration of surgery between the patients of the groups

\begin{tabular}{|l|l|l|l|l|l|}
\hline \multirow{2}{*}{$\begin{array}{l}\text { Duration of } \\
\text { surgery }\end{array}$} & \multicolumn{2}{|l|}{ Group P } & Group T & \multirow{2}{*}{$\begin{array}{l}\text { P } \\
\text { value }\end{array}$} \\
\cline { 2 - 5 } 0-1 hrs & No. & \% & No. & \% & \multirow{2}{*}{ p $=0.120$} \\
\hline $1-2$ hrs & 20 & 50.0 & 13 & 32.5 & \\
\hline $2-3$ hrs & 19 & 47.5 & 22 & 55.5 & \\
\hline Total & 1 & 2.5 & 5 & 12.5 & \\
\hline
\end{tabular}

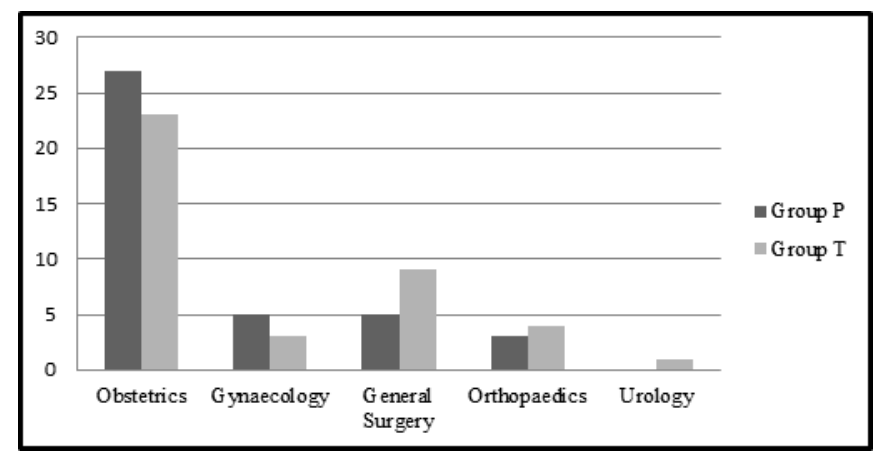

Figure 1 : Comparison of types of surgery in both the group

The baseline parameters were comparable in both groups. There was no statistical difference with regard to the age $(\mathrm{p}=0.384)$ and gender distribution $(\mathrm{p}=0.412)$ or ASA grade $(\mathrm{p}=0.330)$ and the majority of patients belonged to ASA grade 1 as shown in [Table 2]. The duration of surgery was comparable in both the groups with no statistical difference $(\mathrm{p}=0.120)$. Comparison of duration of surgery between the 
groups in depicted in [Table 3]. Types of surgery in the study are depicted in [Figure 1].

\section{Comparison of Shivering in Both the groups}

Both the groups were comparable with regard to grade of shivering and statistically not significant $(\mathrm{p}=0.404)$. The majority of patients in both groups experienced grade1 shivering, $62.5 \%$ in grade 1 in group $\mathrm{P}$ and 67.5 in group $\mathrm{T}$ as shown in [Table 4].

Table 4: Comparison of Grades of Shivering between the patients of two groups

\begin{tabular}{|c|c|c|c|c|c|}
\hline \multirow{2}{*}{ Classification } & \multicolumn{2}{|c|}{ Group P } & \multicolumn{2}{|c|}{ Group T } & \multirow{2}{*}{ P value } \\
\hline & No. & $\%$ & No. & $\%$ & \\
\hline Grade 0 & 6 & 15.0 & 2 & 5.0 & \multirow[t]{4}{*}{$\mathrm{p}=0.404$} \\
\hline Grade 1 & 25 & 62.5 & 27 & 67.5 & \\
\hline Grade 2 & 9 & 22.5 & 11 & 27.5 & \\
\hline Grade 3 & 0 & 0.0 & 0 & 0.0 & \\
\hline
\end{tabular}

Time of onset of shivering in minutes is statistically similar between two groups with $\mathrm{P}=0.331$. In both the groups shivering started within 10 mints after administration of regional anesthesia in the majority of patients [Figure 2]. The time of onset of disappearance of shivering after drug administration was within 2 minutes in $97.5 \%$ of patients in Group $\mathrm{P}$ and in $92.5 \%$ of patients in Group T. Thus the time of onset of disappearance of shivering is similar in the two groups which are statistically proved [Figure 3].

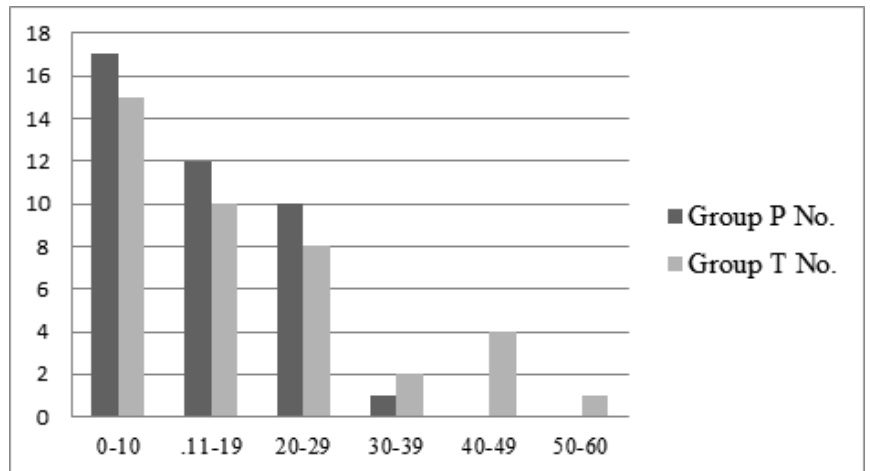

Figure 2: Comparison of Time of onset of appearance of shivering (in minutes) in both the groups

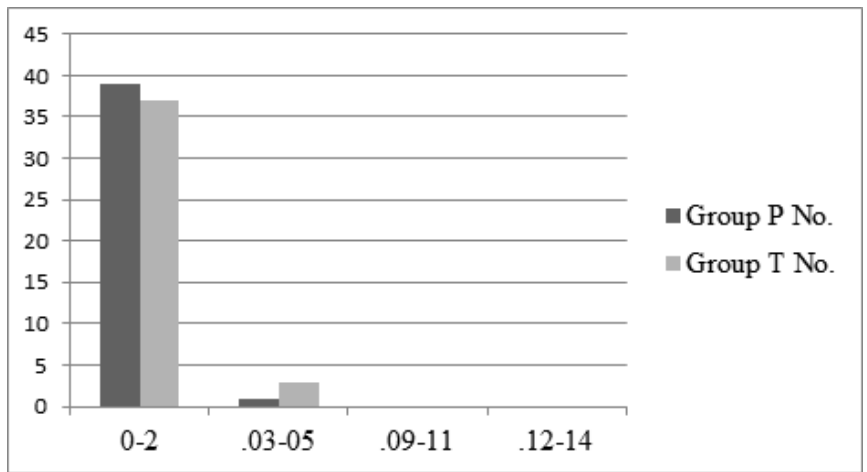

Figure 3: Comparison of Time of onset of disappearance of shivering (in minutes) in the two groups

The complete disappearance of shivering was within 5 mints in $95 \%$ of patients in Group $\mathrm{P}$ and in $82.5 \%$ of patients in Group $\mathrm{T}$. The above results indicate that both the drugs are equally effective in controlling the shivering within similar time duration. There was no statistical difference between the 2 groups $(p=0.383)$. Time taken for complete disappearance of shivering after 5 minutes interval is however statistically more in Group T ( $17.5 \%$ vs $5 \%$ in Group P) with $\mathrm{p}=0.154$. All the shivering stopped within 30 minutes after the administration of the first dose of the drug [Figure 4].

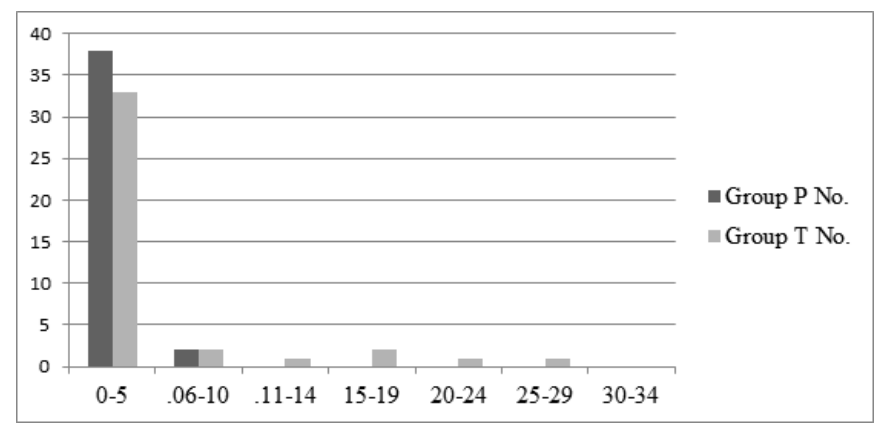

Figure 4: Comparison of Time of complete disappearance of shivering in minutes

The recurrence of shivering occurred in 11 patients in the tramadol group as compared to only 2 patients in the pethidine group which is statistically significant as shown in [Table 5].

Table 5: Comparison of Time of recurrence of shivering in minutes

\begin{tabular}{|l|l|l|l|l|}
\hline \multirow{2}{*}{$\begin{array}{l}\text { Time of recurrence of } \\
\text { shivering in minutes }\end{array}$} & \multicolumn{2}{|l|}{ Group P $(\mathbf{n}=\mathbf{4 0})$} & \multicolumn{2}{l|}{ Group T $(\mathbf{n}=\mathbf{4 0})$} \\
\cline { 2 - 5 } & No & \% & No & \% \\
\hline $0-10$ & 0 & 0.0 & 1 & 2.5 \\
\hline $11-20$ & 0 & 0.0 & 2 & 5.0 \\
\hline $21-30$ & 0 & 0.0 & 4 & 10.0 \\
\hline $30-40$ & 0 & 0.0 & 1 & 2.5 \\
\hline $41-50$ & 2 & 5.0 & 1 & 2.5 \\
\hline $51-60$ & 0 & 0.0 & 1 & 2.5 \\
\hline $61-70$ & 0 & 0.0 & 1 & 2.5 \\
\hline
\end{tabular}

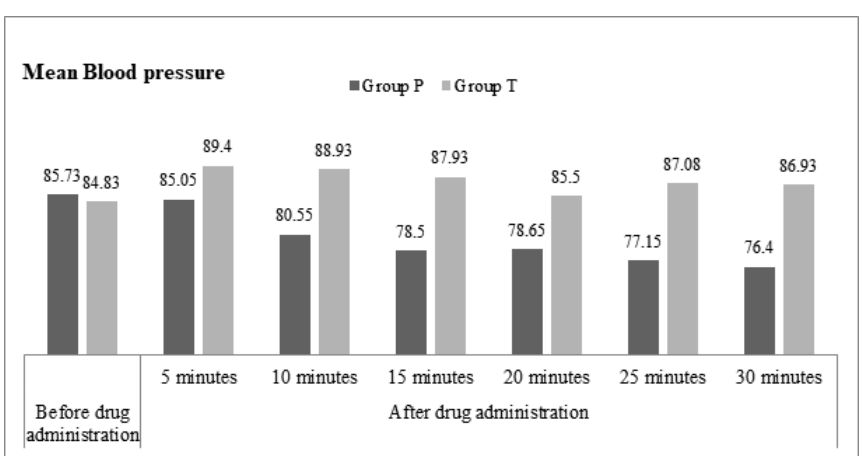

Figure 5: Comparison of Mean Blood Pressure between Group $P$ and Group $T$

\section{Comparison of complications in both the groups:}

There were no significant differences in the pulse rate and temperature between the two groups. Most of the other complications noted were higher in the pethidine group.

The drop in mean blood pressure was significantly higher in the pethidine group 10 minutes after drug administration. The values for Mean BP are presented in [Figure 5].

Other complications included: Respiratory depression with $\mathrm{SpO}_{2}$ of $<94 \%$ ( 8 patients in group ' $\mathrm{P}$ ' vs 1 patient in group ' $\mathrm{T}$ '), (SpO2 was used as a surrogate marker for respiratory depression), sedation (31 patients in group ' $\mathrm{P}$ ' vs 8 patients in group ' $\mathrm{T}$ '). itching ( 2 patients in group ' $\mathrm{P}$ ' vs 0 patients in 
group ' $\mathrm{T}$ '), nausea and vomiting ( 3 patients in group ' $\mathrm{P}$ ' vs 2 patients in group ' $\mathrm{T}$ ') in spite of receiving prophylactic ondansetron. Comparison of complication is represented in [Figure 6].

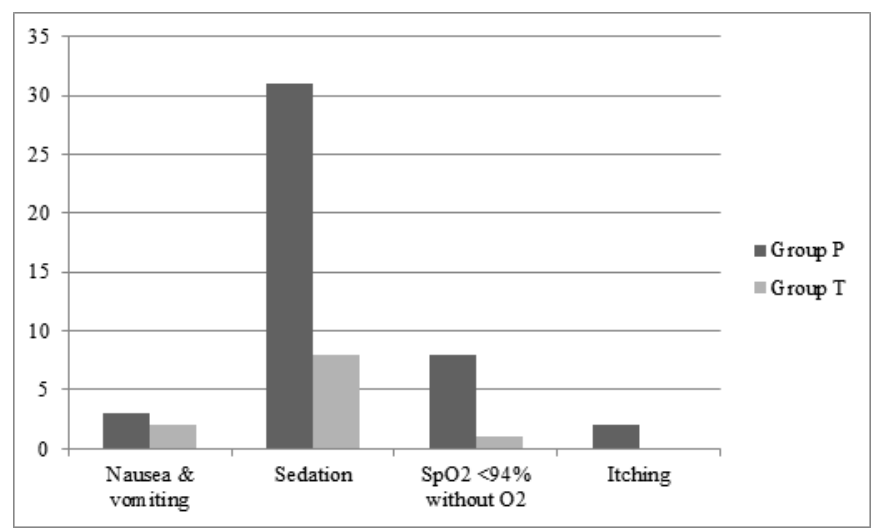

Figure 6: Comparison of type of complications between Group $P$ and Group $T$

\section{Discussion}

Central Neuraxial Blockade (CNB) is a safe and popular anaesthetic technique for various surgeries especially those below the umbilicus. It is widely employed as it is simple to administer, with rapid onset and offset of sensory and motor block and has few complications. Shivering is however a common complication encountered following CNB anaesthesia, the incidence being 40- $60 \%$. ${ }^{[1]}$

Shivering occurs in about $50 \%$ of patients with a core temperature of 35.5 degree centigrade and in $90 \%$ of patients with a core temperature of 34.5 degree centigrade. ${ }^{[2]}$ The mechanism of shivering under regional anaesthesia has, however, not been fully established. The hypotheses which have been postulated are; internal redistribution of heat from the core to the peripheral compartment, the loss of thermoregulatory vasoconstriction below the level of blockade resulting in increased heat loss from the body surfaces in excess of metabolic heat production, altered thermoregulation characterized by a small $(\neg 0.5$ degree Celsius) decrease in vasoconstriction and a slight increase in the sweating threshold. ${ }^{[5]}$ Decrease in core temperature may also be due to hypothermia secondary to a cold operating room or the rapid infusion of crystalloid solutions at room temperature or from the direct effects of cold anaesthetic solutions upon thermo sensitive structures within the spinal cord. ${ }^{[6,7]}$ Prospective randomized data suggest that high risk patients whose core temperatures were $1.3^{\circ} \mathrm{C}$ less than normal were 3 times more likely to experience adverse myocardial outcomes. ${ }^{[2]}$ Marked increase in plasma catecholamine level is perhaps associated with high risk cardiac complications. ${ }^{[3]}$ The temperature recorded in the present study was between $35.7^{\circ} \mathrm{C}$ and $35.9^{\circ} \mathrm{C}$. Of note is that most of the patients in this study were hypothermic with temperature, less than $36^{\circ} \mathrm{C}$.

Various pharmacological and non-pharmacological methods have been employed for control of shivering. ${ }^{[8]}$ The most commonly used drug for control of shivering appears to be pethidine. ${ }^{[9]}$ Pethidine is a synthetic opioid agonist at mu and kappa receptors. The anti shivering activity of pethidine may be partially mediated by k-opioid receptors. ${ }^{[10,11]}$ Pethidine decreases the shivering threshold almost twice as much as vasoconstriction threshold and is an effective treatment for shivering. However, it has been associated with nausea, vomiting, sedation and respiratory depression. A major drawback is that it is a controlled drug and not easily available.

The present study was conducted to evaluate the efficacy and potency of tramadol as an alternative to pethidine for the control of shivering. Tramadol is a centrally acting analgesic with moderate affinity for mu receptors and weak kappa and delta opioid receptor affinity. Tramadol also enhances the function of the spinal descending inhibitory pathways by inhibition of neuronal reuptake of norepinephrine and 5hydroxytryptamine (serotonin) as well as presynaptic stimulation of $5-\mathrm{HT}$ release. ${ }^{[12,13]}$ Tramadol prevents shivering by inhibiting the reuptake of norepinephrine and serotonin. $^{[14]}$

In our study it was observed that in the majority of cases shivering occurred within 10 minutes after the institution of regional anaesthesia with the study drug being administered within 5 minutes after the onset of shivering in all the cases. The 'onset of disappearance' of shivering after the administration of the study drug was within 2 minutes in the majority of cases in both the groups $(97.5 \%$ in the pethidine group and $92.5 \%$ in the tramadol group). There was no statistical difference in the onset of disappearance between the 2 groups $(\mathrm{p}=0.615)$. However, the complete disappearance of shivering' occurred within 2 minutes in $95 \%$ of patients in pethidine group but only in $82.5 \%$ of patients in tramadol group.

2 patients in group ' $\mathrm{P}$ ' required another 5 minutes for shivering to disappear while 7 patients in group ' $\mathrm{T}$ ' required from 10-30 minutes for shivering to disappear. Time taken for complete disappearance of shivering after 5 minutes interval period is statistically more in Group $\mathrm{T} \quad(17.5 \%$ vs $5 \%$ in Group P) with $\mathrm{p}=0.154$.

There is no uniformity in findings pertaining to the use of pethidine and tramadol for post operative shivering in studies undertaken by others, most of them reporting a longer duration to stop shivering with pethidine unlike in our study. It was reported that the onset of disappearance of shivering took longer with pethidine (1 minute in the case of tramadol and 5 minutes in the case of pethidine) and the complete disappearance of shivering occurred by the end of 5 minutes in case of tramadol and 20 minutes in the pethidine. ${ }^{[15-17]}$

Bhatnagar et al using $1 \mathrm{mg} / \mathrm{kg}$ of tramadol and $0.5 \mathrm{mg} / \mathrm{kg}$ of pethidine (half the dose we used) found the tramadol group stopped shivering in 10 minutes while the pethidine group took 40 minutes to stop shivering. ${ }^{[18]}$ De Witte et al found no difference with 1 or $2 \mathrm{mg} / \mathrm{kg}$ tramadol in the time it took for shivering to stop. ${ }^{[12]}$

However, Yousaf et al in their study found the peak antishivering effect of tramadol after about 30 minutes of its iv administration, ${ }^{[17]}$ which is similar to the longer duration taken for complete disappearance of shivering with tramadol as compared to that of pethidine in our study.

Literature on the pharmacokinetics of intravenous tramadol in humans is lacking, hence the exact onset of action of tramadol and its peak effect could not be ascertained, while the onset of action of intravenous pethidine is within 5 
minutes and peak effect is found within 5-10 minutes. ${ }^{[17]}$

Dhimar et al. reported a $50 \%$ recurrence rate with pethidine as opposed to $10 \%$ of patients with tramadol. This is at variance with the results of our study. ${ }^{[1]}$

In our study, recurrence of shivering occurred in 11 patients in the tramadol group as compared to 2 patients in pethidine group which is strongly significant statistically $(27.5 \%$ vs $5.0 \%$ ) with $\mathrm{p}=0.006$. Even Bhatnagar et al. in his study has reported a $50 \%$ recurrence of shivering in the pethidine group within 10 minutes of the initial response, but the dose used in their study was pethidine $0.5 \mathrm{mg} / \mathrm{kg}$ unlike a dose of $1 \mathrm{mg} / \mathrm{kg}$ in our study. So whether a dose of $1 \mathrm{mg} / \mathrm{kg}$ of pethidine is necessary to prevent recurrence of shivering is debatable and needs further studies in this regard. ${ }^{[18,19]}$ In our study a second dose of the study drug was administered in a dose of $0.5 \mathrm{mg} / \mathrm{kg}$ intravenously for patients with recurrence of shivering. The shivering was abolished with both tramadol and pethidine.

We tried to look at the relation between the duration of surgery and the recurrence of shivering as we suspected that the cool ambient temperature had a part in the recurrence of shivering. However we found no relation between the two. In 5 patients recurrence of shivering appeared during the surgery lasting for 1 hour while 7 patients during surgeries lasting 2 hours and 1 patient during a surgery lasting 3 hours. There were no significant differences in the pulse rate between the two groups after drug administration. However the drop in blood pressure was significantly higher in the pethidine group 10 minutes after drug administration as compared to the tramadol group. Unlike earlier studies that have not found any hemodynamic disturbances in any of the groups. Whether the drop in mean blood pressure in the pethidine group was related to the administration of oxytocin during caesarean sections, but to the contrary, we found more cases of caesarean sections in the tramadol group where there was no appreciable fall in blood pressure. ${ }^{[20,21]}$ Therefore, the drop in mean blood pressure may not be due to oxytocin. Previous studies fail to show any respiratory depression even with $1 \mathrm{mg} / \mathrm{kg}$ dose of pethidine. However, in our study $\mathrm{SpO} 2$ dropped below $94 \%$ in 8 patients in the pethidine group as opposed to 1 patient in the tramadol group, which is statistically significant with a $\mathrm{p}$ value $=0.029$. This drop in saturation was not sustained and easily reverted with administration of oxygen by a Hudson mask. The temperature as measured by the tympanic temperature probe was similar in both the groups. ${ }^{[22,23]}$

\section{Conclusion}

The present study results may conclude that tramadol being an easily available drug with similar efficacy in the control of shivering with more stable hemodynamic and fewer side effects such as sedation, respiratory depression, nausea, vomiting and itching may be used safely for control of shivering especially in situations where pethidine is unavailable or where it ought not to be used as in obese patients, lack of adequate post operative monitoring facilities, atopic individuals and patients with known allergy to pethidine. However one must be prepared for a slight delay in the onset of its action and expect a recurrence of shivering which may require further therapy. Pethidine, with its equal efficacy, however may be advocated in patients allergic to tramadol and where sedation is desirable. Further, large prospective studies are required to confirm these findings.

\section{References}

1. Dhimar A, Patel M, Swadia V N. Tramadol for control of shivering Indian journal of anaesthesiology. 2007; 51(1); 28-31.

2. Frank S M, Fleisher L A, Breslow M J. Perioperative maintenance of normothermia reduces the incidence of morbid cardiac events. A randomized clinical trial. JAMA. 1997; 277: 1127-34.

3. Frank S M, Higgins M S, Breslow M J. The catecholamine, cortisol and hemodynamic responses to mild perioperative hypothermia. A randomized control trial. Anaesthesiology. 1995; 82: 83-93.

4. Zahedi H. Comparison of tramadol and pethidine for post anaesthetic shivering in elective cataract surgery. Int J Res Med Sci. 2004;9(5):1-3

5. Bhattacharya P, Bhattacharya L, Jain R, Agarwal R. Post anaesthesia shivering. A review. Indian J Anaesth. 2003; 47(2): 88-93.

6. Mathews S, Al Mulla, Varghese P K, Radim K, Mumtaz S. Post anaesthesia shivering. A new look at tramadol. Anaesthesia. 2002; 57: 387-403.

7. Stoelting R K, Hillier S C. Pharmacology and physiology in anaesthetic practice; 4th edition: 102-104,117.

8. Chan H, Jacobus NK, Tong EW. Control of shivering under regional anaesthesia in obstetric patients with tramadol. Canadian J Anaesth 1999; 46:3, 253-258.

9. Wrench IJ, Cavill G, Ward JEH and Crossley AWA. Comparison between alfentanil, pethidine and placebo in the treatment of postanaesthetic shivering. British J Anaesth. 1997; 79: 541-542.

10. Pauca AL, Savage RT, Simpson S and Roy RC. Effect of pethidine, fentanyl and mohine on post operative shivering in man. Acta Anaesthesiol Scand. 1984;28: 1138-1143.

11. Alfonsi Pascal, Sessler Daniel, Manoir Bertrand, Levron Jean-Claude Levron, Moing Jean-Pierre, Chauvin Marcel. The effects of pethidine and sufentanil on the shivering threshold in postoperative patients. Anaesthesiology. 1998; 89: 43-48.

12. Witte J, Deloof T, Veylder J, Housmans P R. Tramadol in the treatment of post anaesthetic shivering. Acta Anaesth Scand. 1997; 41 506-510.

13. Saha E, Ray M, Mukherjee G. Effect of tramadol in prevention of post anaesthetic shivering following general anaesthesia for cholecystectomy. Indian J Anaesth. 2005; 49(3):208-212.

14. Tsai Chuan, Chu Koung- Shing. A comparison of tramadol, amitriptyline and mepiridine for post epidural anaesthetic shivering in parturients. Anaesth Anal. 2001; 93: 1288-1292.

15. Mokhtarani Masoud, Mahgoub Adel, Morioka Nobutada, Doufas Anthony, Dae Michael, Shaughnessy Thomas, et al. Buspirone and Meperidine synergistically reduce the shivering threshold. Anaesth Anal. 2001;93:1233-9.

16. Chestnut, Obstetric Anaesthesia Principles and practice e-book. 1989; 22: 439

17. Beena Yousaf, Khalid Samad, Hameed Ullah, and Muhammad Q Hoda. Efficacy of tramadol in preventing post operative shivering using thiopentone or propofol as induction agent, A randomized controlled trial. J Anaesth Clin Pharmacol. 2013; 29: 521-525.

18. Bhatnagar S, Saxena A, Kannan T R, Punj J. Tramadol for Postoperative Shivering: A double blind comparison with Pethidine. Anaesth Intensive Care. 2001; 149-154.

19. De Witte J, Kim JS, Sessler D, Bastanmehr and Bjorksten A. Tramadol reduces the sweating, vasoconstriction and shivering thresholds. Anaesth Anal. 1998; 87: 173-179.

20. Davies N.J.H, Cashman J.N; Lee's synopsis of anaesthesia, 13th edition, 477.

21. Roy J D, Girard M, Drolet P. Intrathecal Meperidine decreases shivering during caesarean delivery under spinal anaesthesia. Anaesth Anal. 2004; 98: 230-234.

22. Sessler D. Temperature monitoring; Miller textbook of Anaesthesiology, 6th edition: 1582-1586.

23. Grond S, Sablotzki A. Clinical pharmacology of tramadol. Clin Pharmacokinet: 2004; 43 (13): 879-923. 
Copyright: (c) the author(s), 2020. It is an open-access article distributed under the terms of the Creative Commons Attribution License (CC BY 4.0), which permits authors to retain ownership of the copyright for their content, and allow anyone to download, reuse, reprint, modify, distribute and/or copy the content as long as the original authors and source are cited.

How to cite this article: Prameela VS, Kumar BSM, Kumar B. Comparison of Tramadol and Pethidine for Control of Shivering Following Central Neuraxial Blockade. Anesthesia. Acad. Anesthesiol. Int. 2020;5(1):179-184.

DOI: dx.doi.org/10.21276/aan.2020.5.1.38

Source of Support: Nil, Conflict of Interest: None declared. 